\title{
The Innovation of Thai Silk for Design and Production of Muslim Women Dresses
}

\author{
Srikanjana Jatuphatwarodom ${ }^{1, \mathrm{a}}$, Sakorn Chonsakorn ${ }^{1, \mathrm{~b}}$, Suttila Sawanaporn ${ }^{1, \mathrm{c}}$, Suladach Chupinijrobkob ${ }^{1, \mathrm{~d}}$, \\ Waraporn Wongpatham ${ }^{1, \mathrm{e}}$, Uraiwan Khumsingha ${ }^{1, \mathrm{f}}$, Kornnut Suksawad ${ }^{1, \mathrm{~g}}$, Kittiyaphan Pholam ${ }^{1, \mathrm{~h}}$, \\ Chanakarn Ruangnarong ${ }^{1, \mathrm{i}}$, Natawat Jatuphatwarodom ${ }^{1, \mathrm{j}}$, Rattanaphol Mongkholrattanasit ${ }^{2, \mathrm{k}}$ \\ ${ }^{1}$ Department of Textile \& Clothing, Faculty of Home Economics Technology, Rajamangala University of Technology \\ Thanyaburi, Rangsit Nakhanayok Road, Thanyaburi, Khang 6, Pathumtani, 12110, THAILAND \\ ${ }^{2}$ Department of Textile Chemistry Technology, Faculty of Industrial Textiles and Fashion Design, Rajamangala University \\ of Technology Phra Nakhon, 517, Nakhonsawan Road, Kwang Suan Chitladda, Dusit District, Bangkok, 10300 THAILAND \\ asrikanjana555@hotmail.com, bcsakorn@hotmail.com, \\ cl_suttila@ hotmail.com, ${ }^{\mathrm{d}}$ suladach2606@yayoo.co.th, ${ }^{\mathrm{e}} \mathrm{w}$ _. wongpathamp@hotmail.com, ${ }^{\mathrm{f}}$ ukhumsingha@yahoo.com, \\ ssuppachai18@hotmail.com, hk_pholam@yahoo.co.th, ${ }^{\mathrm{i}}$ rchanakarn@yahoo.com, jarpartpon666@hotmail.com, \\ krattaphol.m@rmutp.ac.th
}

\begin{abstract}
The objectives of this research were 1) to develop Thai silk fabric for production of Muslim women's dresses; 2) to develop a design approach and to produce dresses from Thai silk fabric; 3) to develop a Thai silk and Muslim clothing industry for export. The research methodology were 1) to test finishing silk fabrics for softness and wrinkle-resistant, testing of physical ability and then selecting one of those fabrics to be made into a garment; 2 ) to design and produce garments from the selected Thai silk fabrics, which will then be decorated with the registered Thai silk fabrics as follows: brocaded silk from Lamphun province, Praewa silk from Kalasin province, and Mudmee silk from Khon Kaen province; 3) to propose the results to Thai silk and Muslim clothing manufacturers. The statistics used were percentage, average, standard deviation and t-test. The results found that 1) the silk fabric from Chiang Mai province was the most suitable for making Muslim dresses. The self-reform ability from softness finishing was $92.78 \%$, and $88.89 \%$ from wrinkle-resistant finishing. The weight scale of softness finishing was $\mathbf{7 7 . 6 0}$ grams per square meter; wrinkle-resistant finishing was $\mathbf{8 1 . 6 0}$ grams per square meter. The test fastness of the color staining level of 4-5 or no color changed and the color fastness to light was mediumrated. 2) Loose-fitting garments are more popular than tightfitting ones; Lamphun province's fabrics were found to be the best in terms of decorations. 3) By attending the courses, there were significate changes regarding knowledge, improvement at .05 , and attendees received the most benefits from pattern making and Muslim clothing producing (at 4.70).
\end{abstract}

Keywords-thaisilk; hijab; abaya.

\section{INTRODUCTION}

Muslim women wear a black garment called Abaya and Hijab for headwear while they are away from home. These clothing items are often made in China and India. There is a value of 96,000 million US dollars per year in Islamic fashion markets. The French Fashion University in Esmond, Dubai has also found that about $50 \%$ of Muslims (1.6 billion) spend more than 120 US dollars or about 3,960 Thai baht per person per month for purchasing clothing and jewelry. Especially, Arabian women's clothing market has a high demand, in which the value of one piece of clothing can be as high as 10,000 US dollars or about 330,000 Thai baht. The United Arab Emirates (UAE) is the most important competitive country with Thailand in terms of a cooperative group of countries in the Gulf Cooperation Council (GCC), in which the value of exports has increased to $63.20 \%$. These countries include Saudi Arabia, Oman, Qatar, Kuwait, and Bahrain [1].

According to the information above, there is an opportunity for Thailand to develop Thai silk fabric to achieve easy care functions, to bring quality silk fabrics to be designed and produced into Muslim women's dresses, in particular Abaya and Hijab, and decorated with traditional silk fabrics that are unique and can never be repeated. Several Thai silk clothing manufacturers have been respected by many well-known international brands. The greater expansion of Muslim clothing markets will benefit Thai silk markets. This will provide an opportunity for Thai native fabric producers to create Abaya and Hijab products using Thai silk to a global market. Moreover, Muslim women will also continue the legacy of Thai silk fabric and Thai handicraft.

\section{EXPERIMENT}

A. Material and methods

\section{1) Material and Equipment}

a) Material

Black thin fabric (1 Ply silk), medium thick fabric (2 Ply silk), and thick fabric (4 Ply silk) from four parts of Thailand, which are brocaded silk fabric from Lamphun province, Praewa silk fabric from Kalasin province, and Mudmee silk fabric from Khon Kaen province. The samples can be seen in fig. 1 


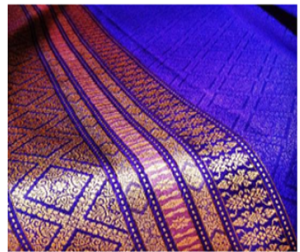

A

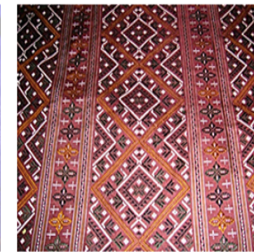

B

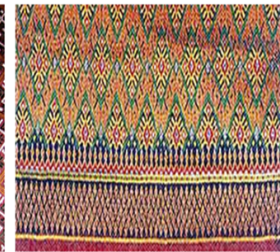

C
Figure 1. A: Brocaded Silk fabric B: Praewa silk fabric C: Mudmee silk fabric

Source: [2]

Softness finishing on fabrics: Cationic (TEXAMINA CA/2), Nonionic (MACROSIL KS). Chemical resistant: Arkofix NZK CN liq. Wrinkle-resistant finishing: LAVA PRET RFB. Water absorber: PU RESIN (Hydropem PRUM. TH liq)

b) Equipment

The equipment in the textile testing laboratory and the equipment in the industrial clothing's design and sewing room.

\section{2) Methods}

a) Develop Thai silk for production of Muslim women's dresses

Black silk fabrics from parts of Thailand were brought for finishing softness and wrinkle-resistance, and then tested for physical ability. One of these fabrics was selected to be made into a garment.

b) Develop a design approach and produce garments from the Thai silk fabrics

- Design and produce prototype dresses (Abaya and Hijab), which were then divided into 2 groups: loose-fitting and tight-fitting. Both groups were decorated with selected black Thai silk fabrics (20 dresses in total).

- Decorate all of those dresses by using brocaded silk, Praewa silk, and Mudmee silk.

- Muslim women were surveyed regarding satisfaction of the developed dresses.

c) Develop Muslim women's Thai silk clothing industry for exports

- Propose all results to Thai silk and Muslim clothing manufacturers. Knowledge tests both before and after attending the courses were administered; then improvements were proposed for planning for production processes. The statistics used were percentage, average, standard deviation and t-test.

\section{RESULTS AND DISCUSSION}

3.1 The results found that 1 Ply silk fabric from Chiang Mai Province, decorated by softness and crease-proof finishing was soft and smooth. The fabric has gained crease-proof ability and a good hand feel. The weight scale of softness finishing was 77.60 grams per square meter; wrinkle-resistant finishing was 81.60 grams per square meter. When compared to the standard of Thai silk products, it was found that hand-weaved fabric is classified to be a very thin fabric type, which has up to 90 grams per square meter of weight in one area [3]. The self-reform ability from softness finishing was $92.78 \%$, and $88.89 \%$ from wrinkle-resistant finishing. The test fastness of the color staining level 4-5 or no color changed, and the color fastness to light was a medium rate. In summary, 1 Ply silk fabric from Chiang Mai Province is the most suitable for producing Muslim women's dresses.

3.2 The results found that loose-fitting garments are more popular than tight-fitting ones. Brocaded silk from Lamphun province was the most popular because Lamphun's silk has high details and high structures of decorations, which increase its price and satisfaction for Muslim women customers who prefer shiny fabric [4]. At present, there has been developments in fabric within the area of the industry in order to add usage functions. The well-known innovation is Coated Textiles [5]. Other than that, there are developments of chemical textile material projects and finishing by using water and environmental friendly chemicals. Thailand Textile Institute has also brought innovative projects to the Thai silk community enterprise as follows: soft finishes on silk fabric, fixing finishes on silk fabric, aroma finishes on silk fabric by using micro-encapsulation technology, waterproof finishes, and flameproof finishes. If those mentioned finishes are applied with Thai silk fabric, they will add more value [6]. The samples can be seen in fig. 2

3.3 The results found that there were significate changes regarding knowledge improvement of attendees at .05, which included silk's decorations, pattern making and producing Muslim women's clothing. In addition, attendees received the most benefits from pattern making and Muslim clothing production (at 4.70). In term of production efficiency improvement, it was found that the samples of manufacturers have four major problems, which were labourers, tools, materials, and processes. The improvement solutions were advised as 1) to increase working level for all staff, 2) to increase production efficiency and to reduce its capital cost, 3) to internationalise production level, 4) to increase on-time delivery, which was indicated to be a problem due to out-of-date machinery, insufficient working labour, and lack of up to date innovations [7].

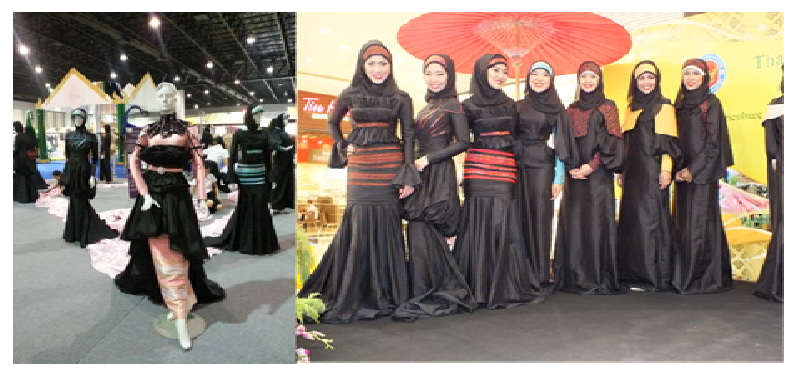

Figure 2. Prototype of Muslim women's Dresses form Thai Silk

\section{CONCLUSIONS}

1 Ply silk fabric from Chiang Mai Province is the most suitable for producing Muslim women's dresses. Loosefitting dresses are more popular than tight-fitting ones. In term of decorations, brocaded silk from Lamphun province 
was the best. Attendees had gained more knowledge compared to before attending the courses. Finally, attendees received the most benefits from pattern making and Muslim women's clothing production. In order to be accepted by the International level, Her Majesty Queen Sirikit of Thailand graciously gave the Thai Peacock brand as the hallmark for grading Thai silk classes, according to their production process into four types as Peacock Gold (Royal Thai Silk), Peacock Silver (Classic Thai Silk), Peacock Blue (Thai Silk) and Peacock (Green). It will be use as a tools for classification the quality of Thai silk with the effectiveness. Offering Thai silk products into global markets is the strategy for economic development. Thus, the Thai silk will be tailored to suit Muslim women (Hijab and Abaya) with the local high quality materials for internationalisation. Outstanding, for instance, Yokmukthaiyan of Saraburi province is from the Central or Phumarang from the South. The north is Namliy of Nan province and Hangkalok of Surin and Buriram province from the Northeast. The different origins has their own characteristics. It brings more innovative furnishings [2]. Consequently, this decorate silk is very special because it made from fabric in different origins. The fabric will be very unique making its soft and durable, increasing the value added obviously. In addition, it will facilitate Thai silk manufacturers in different regions and improve overall of Thai economy in the long run.

\section{ACKNOWLEDGEMENTS}

This research was funded by Rajamangala University of Technology Thanyaburi, Thailand.

\section{REFERENCES}

[1] Thailand's Textile Export Situation on http://www. 2 moc.go.th

[2] Information Systems silk Conservatory on http://qsds.go.th

[3] Thumasiri, K and researcher, Product Development of Thai Silk Quality.Research report: Department of Home Economics, Agriculture, Kasetsart Univesity (2006)

[4] Rules of dress for Muslim women on http://www.islammore.com

[5] Innovative Hand-woven Fabrics on http://www.ttistextiledigest.com

[6] Innovative of Silk Fabrics Finishing on http:// www.ttistextiledigest.com

[7] Yantakun, W. Sewing of Muslim Clothing. Research report: Department of Fashion Design and Textile, Agriculture, Faculty of Architecture. Rajamangala University of Technology Srivijaya (2012) 